\title{
Ultrasonographic evaluation of ureteral stones in children: can we use stone width as a predictor of spontaneous passage?
}

\author{
Ümit Yaşar Ayaz ${ }^{1}$, Alper Dilli ${ }^{2}$, Sevin Ayaz ${ }^{3}$, Arman Api ${ }^{4}$
}

${ }^{1}$ Department of Radiology, Mersin Women's and Children's Hospital, Mersin, ${ }^{2}$ Department of Radiology, Dışkap1 Yıldırım Beyazıt Training and Research Hospital, Ankara, ${ }^{3}$ Department of Nuclear Medicine, Mersin State Hospital, Mersin, ${ }^{4}$ Department of Pediatric Surgery, Mersin Women's and Children's Hospital, Mersin, Turkey

\begin{abstract}
Aims: We aimed to obtain the maximum transverse diameters (widths) of ultrasonographically detectable ureteral stones in children and to evaluate the effect of widths on the rate of spontaneous discharge and on the degree of ipsilateral hydronephrosis. Material and methods: We retrospectively evaluated 52 ultrasonographically detected ureteral stones in 51 consecutive patients ( 32 males, 19 females) with a median age of 9 years (range, 6 months-17 years). Results: In group 1, in which the stones passed spontaneously $(\mathrm{n}=29)$, sonographically measured median and mean widths of ureteral stones were $3.8 \mathrm{~mm}$ (range, 2.3-7.3 mm) and $4.1 \pm 1.3 \mathrm{~mm}$, respectively. In group 2, in which the stones required surgical procedures $(\mathrm{n}=23)$, median and mean widths were $5.9 \mathrm{~mm}$ (range, 3.9-10.0 $\mathrm{mm}$ ) and $5.9 \pm 1.8 \mathrm{~mm}$, respectively. The difference between widths in group 1 and group 2 was significant ( $\mathrm{p}=0.001)$. With regard to the whole study group $(\mathrm{n}=52)$, the majority of the stones below $4.0 \mathrm{~mm}(88.9 \%, \mathrm{n}=16 / 18)$ passed spontaneously and $2 / 3$ of the stones above $5.0 \mathrm{~mm}$ required intervention $(66.7 \%, \mathrm{n}=12 / 18)$. The width range of 4.0-5.0 mm can be accepted as "range of transition" for spontaneous passage and surgical procedures. The stone width was different in patients with mild and severe pelvicaliectasis $(\mathrm{p}=0.0001)$. Conclusions: In children, measuring the width of an ultrasonographically detectable ureteral stone can be useful for assessing its possibility to pass spontaneously. Pelvicaliectasis should be an alerting sign for the presence of an occult ipsilateral ureteral stone in a symptomatic patient.
\end{abstract}

Keywords: ureteral calculi, ultrasonography, pediatrics, urology

\section{Introduction}

Most ureteral stones are in fact renal stones developed in a renal pelvicaliceal system which readily make their way down to ureters. The most common ureteral calcification is a stone that has migrated down from the kidney [1]. Ureteral stone disease is not an uncommon emergency in the pediatric population and requires prompt, accurate diagnosis to exclude other surgical emergencies and

Received 16.06.2014 Accepted 20.07.2014

Med Ultrason

2014, Vol. 16, No 4, 298-303

Corresponding author: Dr. Ümit Yaşar Ayaz, M.D.

Mersin Kadın Doğum ve Çocuk Hastalıkları

Hastanesi, Radyoloji Bölümü,

33240 Halkkent, Mersin, Türkiye

Phone: +90 3242230701

Mobile: +90 5377639442

Fax: +90 3242230722

E-mail: umityasarayaz@yahoo.com to start effective treatment. Excretory urography (EU), transabdominal ultrasonography (US) [2], unenhanced computed tomography (CT) [3-5] and magnetic resonance (MR) urography [6] can be used for this purpose. In the present study, we aimed to obtain the maximum transverse diameters (widths) of ultrasonographically detectable ureteral stones in children and to evaluate the effect of their widths on the rate of spontaneous discharge and on the degree of ipsilateral hydronephrosis.

\section{Material and methods}

\section{Initial evaluation and grouping of the patients}

Between March 2008 and April 2012, 51 consecutive pediatric patients (32 males and 19 females with a median age of 9 years, range, 6 months-17 years) out of 59 , each with at least one ureteral stone on initial US and conformed follow-ups, were included in this retrospec- 
tive study. A total of 52 ureteral stones of the included patients were evaluated. In a 12-year-old male patient, two stones in different ureters were detected consecutively. In each of the rest 50 patients, a single ureteral stone was demonstrated. The patient's loss of contact with our hospital after initial US examination and the patient's having unclear, subtle ultrasonographic records without proper stone size measurements were accepted as exclusion criteria; a total of eight patients were excluded from the study group. All the patients' parents were informed about the procedures and informed consent was obtained. All the procedures were performed according to the World Medical Association Declaration of Helsinki (revised in 2000, Edinburgh).

In all patients the diagnosis of ureteral stone was made by initial US examinations, and clinical outcomes of the patients were obtained. Plain radiographs of abdomen (KUB), EU and the stones which could be obtained from the patients after interventional procedures and spontaneous passage were used to verify the diagnosis, though KUB could not be used in every case for comparison mainly due to excessive bowel gas in many children. In none of the patients with sonographically detected stones, CT was performed for verification or comparison because of the high risks of ionizing radiation for pediatric patients. All of the transabdominal US examinations were performed by the same pediatric radiologist with 10 years' experience in pediatric US practice. A Logic 200 Pro US device (General Electric Medical Systems, Seongnam, Gyeonggi-do, Korea) with 3-3.5 MHz convex-array transducer and $7.5-8 \mathrm{MHz}$ linear-array transducer was used and only gray-scale examination was performed. The patients were held in supine position, semi-lateral and lateral decubitus positions with mild to moderate bladder filling.

Ureteral stones were divided into two groups. The stones which passed spontaneously were included in group 1 and the ones which required surgical procedures were included in group 2. For all the stones in group 1 and group 2, at least one control US examination was done after initial US. Besides US criteria (the absence of a previously detected stone on control US), history of spontaneous passage, relief of symptoms and negative physical examination findings during medical treatment (lasted usually less than one week), were accepted by the pediatric surgeon as clinical criteria for the passage of ureteral stones. In group 2, besides sonographic criteria (the persistence of the stone and hydronephrosis or increase in pelvicalyceal dilatation on control US), the decision for surgical procedures was also clinically made by taking into account the persistence or deterioration of clinical symptoms without any relief during medical treatment (lasted usually more than one week).

\section{Sonographic criteria}

Detection of a hyperechogenic structure with little or prominent posterior acoustic shadowing in the ureter lumen was accepted as diagnostic criteria for the presence of a ureteral stone. The size of the stone was defined as the width of the stone on US. After obtaining the best depictions of the stones on frozen images which were magnified to standard size, measurements were made by using electronic calipers. For standardization, the measurement of a stone was made on the same setting by using the same US device with the same set-up parameters, in the same examination room with similar physical conditions (dark room, etc.). In both groups the ureteral stones were also divided into three subgroups based on their widths: $<4.0 \mathrm{~mm}$, between $4.0-5.0 \mathrm{~mm}$ and $>5.0 \mathrm{~mm}$. On initial sonograms at first referral, locations of the stones in the ureters were divided into three main regions: proximal $1 / 3$, middle $1 / 3$ and distal $1 / 3$ of ureter (including ureterovesical junction). The degree of ipsilateral pelvicaliectasis (hydronephrosis) was graded as none, mild - grade 1 (slight separation/mild dilatation of collecting system with a central ovoid or fusiform sonolucency and blunt appearance of calyces, where echogenic sinus is still demonstrable), moderate - grade 2 (further seperation/advanced dilatation of pelvicaliceal system filling all the sinus area as a rounded sonolucency seen centrally without cortical thinning) and severe - grade 3 (hydronephrosis represents further dilatation of pelvicaliceal system and ballooning of calyces seen as major portion of the kidney replaced by a sonolucent sac with cortical thinning) $[7,8]$.

\section{Statistical analysis}

Descriptive statistics were calculated for all variables. The widths of the stones were compared according to gender and the way of discharge (either spontaneously or by surgical procedures), by using the $t$ test. The ages of the patients in group 1 and group 2 were compared by using the $t$ test. The relationship between the width of the stone and the degree of pelvicaliectasis was evaluated by the one way ANOVA test. The correlation between the width of the stone and the age of the patient was evaluated by the Pearson correlation test. The correlation between the width of the stone and spontaneous passage was evaluated by the Pearson correlation test. $P$ values $<0.05$ were considered as statistically significant. All analyses were done with SPSS software (version 16.0: SPSS Inc, Chicago, IL).

\section{Results}

In the present study, $61.5 \%$ of the stones $(n=32 / 52)$ were located in the right ureter and $38.5 \%$ of them $(n=20 / 52)$ were in the left ureter. Sonographically meas- 
Ultrasonographic evaluation of ureteral stones in children

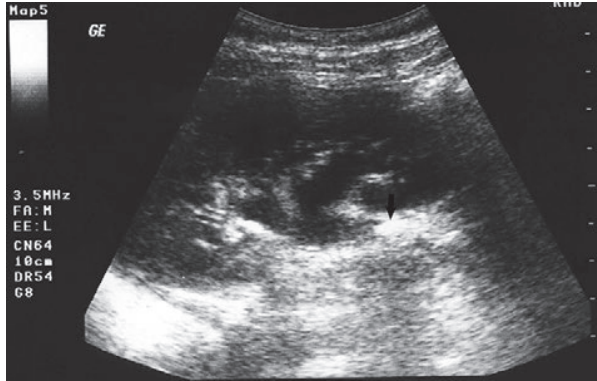

Fig 1. Abdominal US image of a 10-year-old boy. Ureteral stone (arrow) with a width of 4.7 $\mathrm{mm}$ was detected in the proximal end of the right ureter. This stone initially caused obstruction and pelvicaliceal dilatation, but spontaneous passage occurred eventually.

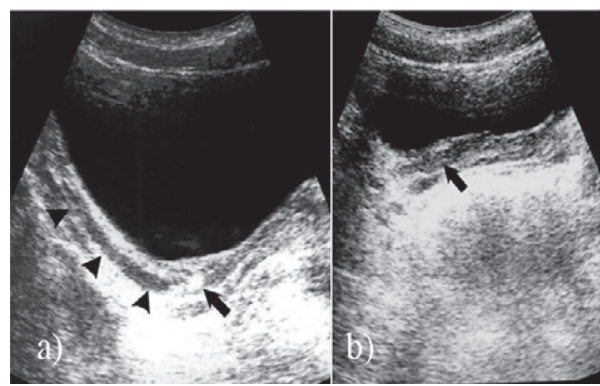

Fig 2. Pelvic US images of a 13 year-old-boy presenting with right flank pain for three days. Ureteral stone (arrow) with a width of $2.6 \mathrm{~mm}$ was detected in the distal end of the dilated right ureter (arrowheads) (a) A few hours after intravenous fluid treatment and medication, the patient discharged the stone and the pain on his right flank was alleviated. The ureteral hyperechogenic structure could no longer be seen in the distal ureter lumen (arrow) (b).

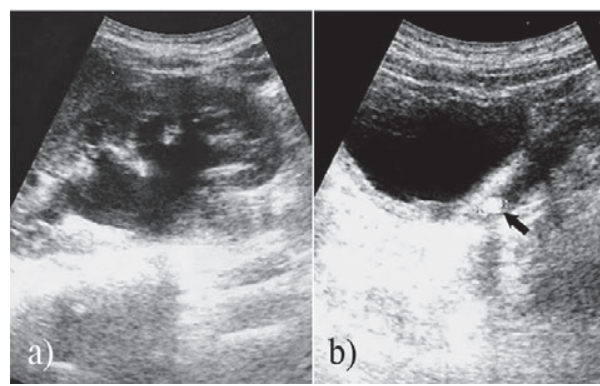

Fig 3. Abdominopelvic US images of the left kidney showing pelvicaliceal dilatation in an eight-year-old boy (a). Ureteral stone (arrow) with a width of $5.3 \mathrm{~mm}$ was detected in the distal end of the dilated left ureter (b). The boy failed to pass the stone spontaneously and required intervention.
Table I. Localization of stones in ureter

\begin{tabular}{lcc}
\hline $\begin{array}{l}\text { Localization of } \\
\text { stones in ureter }\end{array}$ & Group 1 & Group 2 \\
\hline Proximal & $13.8 \%(\mathrm{n}=4 / 29)$ & $39.1 \%(\mathrm{n}=9 / 23)$ \\
Middle & $6.9 \%(\mathrm{n}=2 / 29)$ & $13 \%(\mathrm{n}=3 / 23)$ \\
Distal & $79.3 \%(\mathrm{n}=23 / 29)$ & $47.8 \%(\mathrm{n}=11 / 23)$ \\
Total & $55.8 \%,(\mathrm{n}=29 / 52)$ & $44.2 \%,(\mathrm{n}=23 / 52)$ \\
\hline
\end{tabular}

n- number of stones

Table II. The width of the ureteral stones and their subgrouping

\begin{tabular}{lll}
\hline Ureteral stones & Width of stones & $\begin{array}{l}\text { Percentages and } \\
\text { numbers of stones }\end{array}$ \\
\hline & $* 4.1 \pm 1.3 \mathrm{~mm}$ & \\
& $* * 3.8 \mathrm{~mm}(2.3-7.3)$ & \\
Group 1 & $<4 \mathrm{~mm}$ & $55.2 \%(\mathrm{n}=16 / 29)$ \\
$(\mathrm{n}=29)$ & $4-5 \mathrm{~mm}$ & $24.1 \%(\mathrm{n}=7 / 29)$ \\
& $>5 \mathrm{~mm}$ & $20.7 \%(\mathrm{n}=6 / 29)$ \\
\hline & $* 5.9 \pm 1.8 \mathrm{~mm}$ & \\
Group 2 & $* * 5.9 \mathrm{~mm}(3.9-10.0)$ \\
$(\mathrm{n}=23)$ & $<4 \mathrm{~mm}$ & $8.7 \%(\mathrm{n}=2 / 23)$ \\
& $4-5 \mathrm{~mm} \quad 39.1 \%(\mathrm{n}=9 / 23)$ \\
& $>5 \mathrm{~mm}$ & $52.2 \%(\mathrm{n}=12 / 23)$ \\
\hline *- Mean $\pm S D, * *$ & Median and range, $\mathrm{n}-$ number of stones
\end{tabular}

ured median and mean widths of the stones in the whole study group $(\mathrm{n}=52)$ were $4.6 \mathrm{~mm}$ (range, $2.3-10.0 \mathrm{~mm}$ ) and $4.9 \pm 1.8 \mathrm{~mm}$, respectively. The difference between the widths of the ureteral stones in male and female patients was not significant $(p=0.21)$.

The percentages and numbers of group 1 and group 2 stones were $55.8 \%,(n=29 / 52)$ and $44.2 \%,(n=23 / 52)$, respectively. The localization of the stones is detailed in table I. The median time interval from the onset of symptoms until spontaneous discharge in group 1 was five days (range, $1-50$ days). The median time interval from the onset of symptoms until surgical intervention in group 2 was eight days (range 5-140 days).

Concerning the study group no correlation between the stone width and the age of the patient was found $(p>0.05)$. The patients from group 1 have had an older age $(9.4 \pm 5.2$ years) comparing with patients from group 2 (6.9 94.5 years $)(p=0.001)$. The difference between the stone widths between the two groups was significant $(\mathrm{p}=0.001)$. The mean and median stone widths together with their subgrouping depending on the width are given in table II. The majority of the stones $<4.0 \mathrm{~mm}(88.9 \%, \mathrm{n}=16 / 18)$ passed spontaneously and $2 / 3$ of the stones $>5.0 \mathrm{~mm}$ in width $(66.7 \%, n=12 / 18)$ required surgical procedures (figs $1-3$ ).

On initial US at referral, $94.2 \%(n=49 / 52)$ of the stones had caused mild to severe pelvicaliectasis in the 
Table III. The degree of hydronephrosis and the stones' widths

\begin{tabular}{lcc}
\hline $\begin{array}{l}\text { Degree of } \\
\text { hydronephrosis }\end{array}$ & $\begin{array}{c}\text { Median stone width } \\
\text { and ranges }(\mathbf{m m})\end{array}$ & p value \\
\hline Mild & 3.8 (range $2.3-5.9)$ & \\
Moderate & 5.0 (range $2.6-8.3)$ & 0.0001 \\
Severe & 5.9 (range $3.7-10.0)$ & \\
\hline
\end{tabular}

ipsilateral kidney (table III). The percentages of accompanying ipsilateral single renal stone and ipsilateral multiple renal stones were $11.5 \%(\mathrm{n}=6 / 52)$ and $13.5 \%$ $(\mathrm{n}=7 / 52)$, respectively.

All the patients were discharged from the hospital in good health. However, in a patient with a long-standing ureteral stone, postoperative renal scintigraphy with technetium-99m diethylene triamine penta-acetic acid (Tc-99m DTPA) revealed severe loss of function in the ipsilateral kidney after successful surgical removal of the stone. The patient underwent nephrectomy one year later.

\section{Discussions}

Careful evaluation of the symptoms and signs in pediatric patients suspected of having ureteral stone disease is important in order to avoid loss of time and to perform an initial US examination $[9,10]$.

According to the data obtained in our study, stones $<4.0 \mathrm{~mm}$ are most likely to pass spontaneously, while stones $>5.0 \mathrm{~mm}$ are likely to need surgical procedures. The width range of $4.0-5.0 \mathrm{~mm}$ can be accepted as a "range of transition" for spontaneous passage and surgical procedures. We compared our results with those in the literature. Though Pietrow et al [11] reported that in all pediatric patients the stones greater than $5 \mathrm{~mm}$ rarely had passed spontaneously, we noticed that in a certain number patients with stones $>5 \mathrm{~mm}$ in width, spontaneous passage was possible during medical treatment. Kit et al [10] reported the mean size of spontaneously passed stones as $4 \mathrm{~mm}$. Although Van Savage et al [12] stated that no child spontaneously passed a stone with a size of $4 \mathrm{~mm}$ or greater, we found a considerable number of stones $>4.0 \mathrm{~mm}$ that had passed spontaneously.

The mean age of patients from group 2 were relatively close to the mean ages of children with interventionally treated ureteral stones in other recent studies [13,14]. In our study, besides having stones larger than those of group 1 , the patients with group 2 stones were also younger which might have adversely affected stone discharge. Relatively narrower ureteral lumens of younger patients may have a negative effect on the passage of ureteral stones. But many other individual factors in younger patients (predisposing physiological and anatomical factors, physical and chemical properties of the stones) might have also played a role in their failure of spontaneous passage.

On initial US, the percentage of stones located in the distal $1 / 3$ of ureters were higher in group 1 . This was probably related with a relatively faster movement of the smaller stones down to the distal $1 / 3$ of ureters. In majority of our patients, mild to severe pelvicaliectasis accompanied to ureteral stones. Because of this, pelvicaliectasis should be an alerting sign for the presence of an occult ipsilateral ureteral stone in a symptomatic patient. Azili et al. [15] reported that in $27.6 \%$ of their patients, ureteral stones were accompanied by renal stones which was close to our results. This means that it is more probable not to see an accompanying renal stone with an ipsilateral ureteral stone in the majority of the cases.

In various studies including pediatric patients, US was compared with CT in detection of ureteral and urinary stones $[2,3,16]$. Though low-dose, unenhanced, single detector $\mathrm{CT}$ or multidetector $\mathrm{CT}$ (MDCT) protocols have been emerging in evaluation of adult and/or pediatric patients with renal colic and urolithiasis [17-21], the most important disadvantage of $\mathrm{CT}$ is still its high ionizing radiation dose which prevents $\mathrm{CT}$ to be a repeatable tool particularly in control examinations. Additionally, the occasional need for sedation with CT favours the use of US in infants and young children, whenever it provides the necessary visualization [1]. Though US and CT was reported to be used together in the detection of a pediatric ureteral stone and associated hydronephrosis [22], in the present study US gave us all the useful data when a stone was identified, such as locations and widths of the ureteral stones. Renal scintigraphy with technetium-99m dimercaptosuccinic acid (Tc-99m DMSA) can be used to reveal renal parenchymal scarring in preschool-age children with urolithiasis [23] and can also show the impact of silent ureteral stones on kidneys [24]. In the present study, renal scintigraphy with Tc-99m DTPA was particularly useful to assess the severe loss of function in a patient with long-standing ureteral stone. However, scintigraphic studies using Tc-99m DTPA and Tc-99m DMSA with larger patient population are necessary to evaluate both renal functions and renal parenchymal scarring in children with such long- standing group 2 stones.

The present study had some limitations. We did not calculate the intraobserver differences, which can be accepted as a limitation of the study. However, intraobserver differences were minimal since the measurement of stone widths was made using a standard technique with the same setting, on the same day. Also, control examination of a stone was made by using the same US device with the same set-up parameters in the same examination room. Because the same (single) observer performed US, 
the interobserver differences in the measurements were not calculated and therefore, these were not mentioned in the results. US was reported to overestimate the sizes of urinary tract calculi, particularly of the small ones [25]. Radiologists were also reported to underestimate the smaller urinary-tract stones [26]. In order to avoid overestimation or underestimation of stone widths in our daily practice, we obtained the best depictions of the stones on frozen images which are magnified to standard size and the electronic calipers at the borders of the stone images were placed precisely. According to our results younger patients with larger stones are less likely to pass their stones spontaneously. We could not perform detailed subgroup analysis regarding the patient age in both group 1 and group 2 because of the relatively limited number of patients. Spectral Doppler US was used to demonstrate the effects of interventional treatments such as ESWL on renal blood flow [27]. The use of only gray-scale US without Doppler US could be considered as a limitation for the patients with group 2 stones; however, this was thought to be beyond the scope of our retrospective study.

\section{Conclusions}

In children, measuring the width of an ultrasonographically detectable ureteral stone can be useful for assessing its possibility to pass spontaneously. Pelvicaliectasis should be a warning for the presence of an occult ipsilateral ureteral stone in a symptomatic child and, also, the absence of an ipsilateral renal stone does not exclude an occult ureteral stone in such a patient. Renal scintigraphy should be used for a child with a long-standing stone, in order to detect any renal parenchymal scarring and loss of renal function.

Acknowledgments: We appreciate very much the help of Dr. Sevim Turanlı in the statistical analysis. We thank also Mehmet Ayaz (Çelemli) for his guidance.

Conflict of interest: the authors declared no conflicts of interest.

\section{References}

1. Hoppe B, Kemper MJ. Diagnostic examination of the child with urolithiasis or nephrocalcinosis. Pediatr Nephrol 2010; 25: 403-413.

2. Mos C, Holt G, Iuhasz S, Mos D, Teodor I, Halbac M. The sensitivity of transabdominal ultrasound in the diagnosis of ureterolithiasis. Med Ultrason 2010; 12: 188-197.

3. Oner S, Oto A, Tekgul S, et al. Comparison of spiral CT and US in the evaluation of pediatric urolithiasis. JBR-BTR 2004; 87: 219-223.
4. Persaud AC, Stevenson MD, McMahon DR, Christopher NC. Pediatric urolithiasis: clinical predictors in the emergency department. Pediatrics 2009; 124: 888-894.

5. Shokeir AA, Abdulmaaboud M. Prospective comparison of nonenhanced helical computerized tomography and Doppler ultrasonography for the diagnosis of renal colic. J Urol 2001; 165: 1082-1084.

6. Grattan-Smith JD, Jones RA. MR urography in children. Pediatr Radiol 2006; 36: 1119-1132.

7. Dogra V, Rubens DJ (eds). Ultrasound Secrets. Philadelphia: Hanley and Belfus, 2004.

8. Ellenbogen PH, Scheible FW, Talner LB, Leopold GR. Sensitivity of gray scale ultrasound in detecting urinary tract obstruction. AJR Am J Roentgenol 1978; 130: 731733.

9. Dursun I, Poyrazoglu HM, Dusunsel R, et al. Pediatric urolithiasis: an 8-year experience of single center. Int Urol Nephrol 2008; 40: 3-9.

10. Kit LC, Filler G, Pike J, Leonard MP. Pediatric urolithiasis: experience at a tertiary care pediatric hospital. Can Urol Assoc J 2008; 2: 381-386.

11. Pietrow PK, Pope JC 4th, Adams MC, Shyr YU, Brock JW 3rd. Clinical outcome of pediatric stone disease. J Urol 2002; 167: 670-673.

12. Van Savage JG, Palanca LG, Andersen RD, Rao GS, Slaughenhoupt BL. Treatment of distal ureteral stones in children: similarities to the american urological association guidelines in adults. J Urol 2000; 164: 1089-1093.

13. Gecit I, Pirincci N, Günes M, et al. Should ureteroscopy be considered as the first choice for proximal ureter stones of children? Eur Rev Med Pharmacol Sci 2013; 17: 18391844.

14. Tiryaki T, Azili MN, Özmert S. Ureteroscopy for treatment of ureteral stones in children: factors influencing the outcome. Urology 2013; 81: 1047-1051.

15. Azili MN, Ozcan F, Tiryaki T. Retrograde intrarenal surgery for the treatment of renal stones in children: Factors influencing stone clearance and complications. J Pediatr Surg 2014; 49: 1161-1165.

16. Passerotti C, Chow JS, Silva A, et al. Ultrasound versus computerized tomography for evaluating urolithiasis. J Urol 2009;182: 1829-1834.

17. Heneghan JP, McGuire KA, Leder RA, DeLong DM, Yoshizumi T, Nelson RC. Helical CT for nephrolithiasis and ureterolithiasis: comparison of conventional and reduced radiation-dose techniques. Radiology 2003; 229: 575-580

18. Tack D, Sourtzis S, Delpierre I, de Maertelaer V, Gevenois PA. Low-dose unenhanced multidetector CT of patients with suspected renal colic. AJR Am J Roentgenol 2003; 180: 305-311.

19. Poletti PA, Platon A, Rutschman OT, Schmidlin FR, Iselin CE, Becker CD. Low-dose versus standard-dose CT protocol in patients with clinically suspected renal colic. AJR Am J Roentgenol 2007; 188: 927-933.

20. Karmazyn B, Frush DP, Applegate KE, Maxfield C, Cohen $\mathrm{MD}$, Jones RP. CT with a computer-simulated dose reduc- 
tion technique for detection of pediatric nephroureterolithiasis: comparison of standard and reduced radiation doses. AJR Am J Roentgenol 2009; 192: 143-149.

21. Ciaschini MW, Remer EM, Baker ME, Lieber M, Herts BR. Urinary calculi: radition dose reduction of $50 \%$ and $75 \%$ at CT-effect on sensitivity. Radiology 2009; 25: 105 111.

22. Jung ES, Yang EM, Kim CJ. Acute kidney injury and postobstructive diuresis caused by a $4 \mathrm{~mm}$ urinary calculus. J Korean Soc Pediatr Nephrol 2013; 17: 117-121.

23. Elmacı AM, Ece A, Akın F. Clinical characteristics and metabolic abnormalities in preschool-age children with urolithiasis in southeast Anatolia. J Pediatr Urol 2014; 10: 495-499.
24. Marchini GS, Vicentini FC, Mazzucchi E, Brito A, Ebaid G, Srougi M. Silent ureteral stones: impact on kidney function--can treatment of silent ureteral stones preserve kidney function? Urology 2012; 79: 304-308.

25. Ray AA, Ghiculete D, Pace KT, Honey RJ. Limitations to ultrasound in the detection and measurement of urinary tract calculi. Urology 2010; 76: 295-300.

26. Kampa RJ, Ghani KR, Wahed S, Patel U, Anson KM. Size matters: a survey of how urinary-tract stones are measured in the UK. J Endourol 2005; 19: 856-860.

27. Kurt S, Tokgöz Ö, Tokgöz H, Voyvoda N. Evaluation of effects of Extracorporeal Shock Wave Lithotripsy on renal vasculature with Doppler ultrasonography. Med Ultrason 2013; 15: 273-277. 